\title{
Relato da Aplicação de uma Sequência Didática Fundamentada nas Metáforas de Perspectivas Culturais para Fomentação do Pensamento Computacional
}

\author{
Oto B. Assunção ${ }^{1}$, Raquel O. Prates ${ }^{1}$, Elaine S. França ${ }^{2}$ \\ ${ }^{1}$ Departamento de Ciência da Computação \\ Universidade Federal de Minas Gerais (UFMG) - Belo Horizonte, MG - Brazil \\ ${ }^{2}$ Centro Pedagógico da Escola de Educação Básica e Profissional da UFMG \\ \{oto.braz, rprates\}@dcc.ufmg.br, lainesf@ufmg.br
}

\begin{abstract}
The development of Computational Thinking (CT) skills is essential for students who will work in a world constantly changing. This paper reports the experience of conducting evaluating a course taught to middle school students to promote the development of CT. The experience was evaluated according to the students' perceptions, and according to observations carried out by the researchers. The students had positive opinions about the activities and diffculty of the course, and we identified issues that should be addrerssed to improve the course.
\end{abstract}

Resumo. As habilidades do Pensamento Computacional (PC) são essenciais para jovens que atuarão em um mundo constantemente em evolução. Este artigo relata a experiência de condução e avaliação de um curso ministrado a alunos do Ensino Fundamental - Anos Finais para promover o desenvolvimento do PC. Avaliamos a experiência a partir da percepção dos alunos e a partir de observações realizadas por nós ao ministrarmos as aulas. A opinião dos alunos em relação às atividades e a dificuldade do curso foram positivas e, no decorrer do curso, nós identificamos problemas a serem endereçados para aprimorarmos o curso.

\section{Introdução}

A Computação tem se tornado cada vez mais importante para a sociedade contemporânea dada a constante integração de tecnologias digitais nas mais diversas áreas de atuação da sociedade. Especificamente, o desenvolvimento do Pensamento Computacional (PC), ou seja, "a capacidade de sistematizar, representar, analisar e resolver problemas" [SBC 2019], é essencial para jovens que estarão atuando em um mundo dinâmico e lidando com inúmeros problemas, inclusive aqueles que ainda não existem atualmente [Wing 2006, Wing 2011]. Logo, vários países já introduziram a Computação na educação básica por meio da criação de disciplinas específicas ou ao combinar disciplinas regulares com a Computação [Heintz et al. 2016].

No Brasil, a importância da Computação e do PC é reconhecida por professores, por pesquisadores, pela Sociedade Brasileira de Computação [SBC 2019], e também pelo Ministério da Educação, que passou a abordar a Computação e o PC na Base Nacional Comum Curricular [MEC 2018]. Assim, o interesse pelo ensino da Computação 
na educação básica cresceu bastante nos últimos anos [Santos et al. 2018]. Diversas pesquisas envolvendo o PC são relatos de experiência e estudos de caso, onde, similarmente ao nosso trabalho, sequências didáticas elaboradas pelos pesquisadores para o desenvolvimento do PC por meio da lógica de programação são aplicadas e avaliadas. Em [Almeida and Junior 2020] foi relatada a experiência da aplicação de uma sequência didática com alunos do $4^{\circ}$ ano do Ensino Fundamental (EF) utilizando atividades desplugadas, a plataforma Hora do Código e o Scratch. Em [Duarte et al. 2017] e [Carlos et al. 2018], foram propostas sequências didáticas, onde em cada aula é apresentado um tema específico da Computação (e.g.: algoritmos, laços de repetição, depuração, condição), que, em seguida, é trabalhado através de atividades práticas. Contudo, em muitas destas pesquisas, incluindo os trabalhos citados, os autores não disponibilizam os materiais utilizando, dificultando a reprodução da experiência.

Neste artigo, apresentamos e avaliamos a aplicação de uma sequência didática, criada a partir de uma nova abordagem fundamenta nas Metáforas de Perspectivas Culturais para definir recursos didáticos a serem adotados para que a Computação e PC sejam introduzidos gradativamente a alunos do EF - Anos Finais. Esta foi a segunda etapa de um trabalho de mestrado, cujo objetivo final é propor uma sequência didática para ensino da Computação e fomentação do PC nos anos finais do EF. Na primeira etapa, selecionamos recursos didáticos a partir da classificação em [Oliveira et al. 2019] e os utilizamos em um curso para introduzir o PC a 16 alunos do EF II. O curso foi revisado e conduzido novamente com um novo grupo de alunos (11 participantes). Assim, focaremos especificamente na experiência de conduzirmos o curso revisado e os resultados obtidos.

\section{Metodologia}

Este trabalho corresponde à segunda etapa de uma pesquisa-ação [Tripp 2005] conduzida no Centro Pedagógico da Escola de Educação Básica e Profissional da UFMG (CP). A pesquisa foi realizada por meio de um Grupo de Trabalho Diferenciado (GTD), que são disciplinas semestrais de temas variados com aulas de 1h20min ministradas uma vez por semana. O nosso objetivo final é a criação de uma sequência didática para o ensino da Computação e PC a alunos dos anos finais do EF.

Na primeira etapa, nós ministramos o GTD de PC I 2019/1 a 16 alunos do $6^{\circ}$ ano do EF no primeiro semestre de 2019 [Assunção et al. 2019]. Neste GTD, utilizamos diferentes recursos didáticos para o desenvolvimento do PC por meio do aprendizado e prática do pensamento algorítmico. Adotamos a classificação da complexidade de recursos didáticos à luz das Metáforas de Perspectivas Culturais (MPC) [Salgado et al. 2011] realizada em [Oliveira et al. 2019] para selecionarmos ferramentas e atividades que utilizaríamos no GTD. Assim, propomos uma sequência didática a fim de que os alunos experimentassem o PC em níveis graduais de dificuldade. Este GTD foi avaliado segundo a percepção dos alunos participantes e a nossa percepção como pesquisadores/professores que o ministraram. A partir dos resultados, realizamos modificações na sequência didática para mitigarmos pontos negativos do GTD de PC I 2019/1 e, no segundo semestre de 2019, ela foi utilizada no GTD de PC I 2019/2, o qual é o foco do presente artigo.

Onze alunos (5 meninos e 6 meninas) que estavam cursando o $6^{\circ}$ ano do EF participaram do GTD de PC I 2019/2. Eles foram selecionados a partir do protocolo de seleção do próprio CP. Os alunos indicam três GTDs que eles têm interesse em participar e, de 
acordo com a oferta e demanda, os alunos são alocados aos GTDs pelos professores.

Similarmente, avaliamos o GTD de PC I 2019/2 segundo a nossa percepção como professores ministrando o GTD e a percepção dos alunos. Dados sobre a nossa percepção foram coletados por meio da observação participante; e dados sobre a percepção dos alunos, por meio de questionários e grupos focais.

Segundo [Spradley 1980], pesquisadores utilizando a observação participante devem fazer registros objetivos e subjetivos sobre o que está sendo observado. Neste sentido, fizemos registros durante as aulas, os quais foram objetivos e superficiais; e após as aulas, os quais eram subjetivos, explorando e interpretando o que havia sido observado.

Ao final de cada aula, os alunos respondiam um questionário para avaliarem como foi a aula. $\mathrm{O}$ questionário ${ }^{1}$ perguntava aos alunos o quanto eles gostaram da atividade $\mathrm{e}$ o quão difícil foi a atividade. Assim, ele era simples o bastante para ser respondido nos minutos finais das aulas. No fim da experiência, conduzimos os grupos focais com os participantes para obtenção de dados qualitativos referentes às aulas, atividades, ferramentas e ao GTD em geral. Uma aluna não pôde participar deles no dia que os realizamos e acabamos realizando uma entrevista individual com ela. $\mathrm{O}$ mesmo roteiro dos grupos focais foi utilizado para conduzirmos a entrevista, que ocorreu de forma semiestruturada.

\section{Descrição das Aulas e Atividades}

O GTD de PC I 2019/2 teve um total de 11 aulas. Nesta seção, nós apresentamos as aulas e as atividades realizadas em cada um delas. Nós adotamos uma abordagem similar àquela do GTD de PC I 2019/1, onde a maior parte de cada aula foi alocada para a condução de atividades a fim de que os alunos pudessem praticar de forma engajada os tópicos apresentados nos minutos iniciais das aulas.

\section{Aula 1: Raciocínio Lógico}

Na primeira aula, utilizamos o Estacionamento Algorítmico² ${ }^{2}$ Disponibilizamos os quatro primeiros desafios da atividade para os alunos, que estavam sentados em duplas, resolverem e registrarem suas soluções. Cada aluno de cada dupla resolveu dois desafios diferentes (um deles resolveu os desafios de número ímpar; e o outro, os desafios de número par). No GTD de PC I 2019/1, os alunos fizeram o registro das soluções após eles terem resolvido todos os desafios, ficando difícil para que eles lembrassem todos os passos das soluções. Assim, no GTD de PC I 2019/2 pedimos que as soluções fossem registradas assim que um desafio fosse solucionado antes deles tentarem fazer os próximos desafios. Por fim, os alunos passaram suas soluções para um colega de turma testá-las, seguindo os passos e indicando os erros na solução caso eles existissem.

\section{Aula 2: Algoritmos e Sequenciamento de Ações Desplugados}

$\mathrm{Na}$ Aula 2, introduzimos o conceito de algoritmos, fazendo a associação com as soluções do Estacionamento Algorítmico registradas pelos alunos na aula anterior. Em seguida, exibimos um vídeo ${ }^{3}$ demonstrando a importância da definição precisa de instruções e realizamos a atividade Decomposição da Turma da Mônica ${ }^{4}$. Cada aluno decompôs um

\footnotetext{
${ }^{1}$ Questionário - Avaliando a Atividade $[\pi$

${ }^{2}$ Disponível em: https://www.computacional.com.br/\#atividades

${ }^{3}$ Disponível em: https://www.youtube.com/watch?v=pdhqwbUWf4U

${ }^{4}$ Disponível em: https://www.computacional.com.br/\#atividades
} 
dos problemas e, em seguida, discutimos as soluções com a turma, buscando determinar se elas estavam corretas, incorretas e se podiam ser melhoradas. Por fim, o Programando em Papel ${ }^{5}$ foi realizado. Os alunos tiveram que utilizar os comandos para criar algoritmos para colorir 3 figuras. No semestre anterior os alunos reclamaram que muitos exercícios do Programando em Papel tiveram que ser feitos, fazendo com que a aula ficasse repetitiva. Assim, no GTD de PC I 2019/2, o número de exercícios foi reduzido e o vídeo e a atividade de decomposição foram incluídos.

\section{Aula 3: Algoritmos e Sequenciamento de Ações Plugados}

A Aula 3 apresentou bons resultados com a primeira turma, então ela foi mantida a mesma. Primeiramente, foi conduzida uma revisão das aulas anteriores com os alunos utilizando o Kahoot! ${ }^{6}$. Após a revisão, disponibilizamos o link para que os alunos acessassem e resolvessem os desafios do LightBot - Hora do Código ${ }^{7}$.

\section{Aulas 4 e 5: Aprofundando em Algoritmos - Loops}

$\mathrm{Na}$ Aula 4 abordamos a repetição de comandos por meio da lição Labirinto: Ciclos $^{8}$ do Curso 2 da plataforma Code.org, assim como no primeiro semestre. No início da aula, um kahoot ${ }^{9}$ foi conduzido nos minutos iniciais da aula para que os alunos revisassem os desafios básicos do LightBot. Em seguida, apresentamos aos alunos o conceito de laços de repetição, a plataforma Code.org e a linguagem de programação em blocos que os alunos utilizariam para resolver os desafios da lição Labirinto: Ciclos. Durante o restante da Aula 4 e na Aula 5 eles ficaram resolvendo os desafios da lição.

\section{Aula 6: Introdução ao Scratch}

A partir da Aula 6, nós passamos a utilizar o Scratch. Um kahoot ${ }^{10}$ também foi realizado no início da aula para revisar tudo que os alunos tinham aprendido até o momento. Após a revisão, nós apresentamos o Plano Cartesiano aos alunos, que não tinha sido apresentado no GTD de PC I 2019/1 e que nós consideramos importante para que os alunos entendessem os blocos de movimento no Scratch. Os alunos do GTD eram do $6^{\circ}$ ano e ainda não tinham conhecimentos sobre o Plano Cartesiano e número negativos, então estes tópicos foram apresentados de forma simplificada e por meio de exemplos para que eles visualizassem e praticassem a identificação dos pontos no plano. Por fim, apresentamos o Scratch e associamos a explicação do Plano Cartesiano com os blocos de movimento. Junto com os alunos, testamos comandos básicos de movimento, aparência e repetição.

\section{Aula 7: Scratch - Anime seu Nome}

Iniciamos a Aula 7 com uma revisão no Kahoot! ${ }^{11}$ abordando o Plano Cartesiano e blocos de movimento do Scratch na aula anterior. Durante o restante da aula, os alunos desenvolveram projetos do Anime seu Nome, que é uma atividade introdutória no Scratch, onde os alunos devem animar letras de seus nomes, e que todos os alunos do GTD de PC I 2019/1 gostaram de ter feito.

\footnotetext{
${ }^{5}$ Aula 2 - Programando em Papel Simplificado $\widetilde{ }$

${ }^{6}$ Aula 3 - Kahoot de Revisão I $\nearrow$

${ }^{7}$ Aula 3 - LightBot $\nearrow$

${ }^{8}$ Aulas 4 e 5 - Labirinto: Ciclos $匚$

${ }^{9}$ Aula 4 - Kahoot de Revisão II $\widetilde{ }$

${ }^{10}$ Aula 6 - Kahoot de Revisão III $\nearrow$

${ }^{11}$ Aula 7 - Kahoot de Revisão IV $\nearrow$
} 


\section{Aula 8: Condicionais no Scratch - Pong}

No semestre 2019/1, as estruturas condicionais foram praticadas por meio da lição Abelhas: Condicionais do Code.org, cujos desafios requeriam que os alunos utilizassem as condicionais apenas de uma maneira. Logo, consideramos que o desenvolvimento de um jogo para prática das condicionais seria uma abordagem mais eficiente e com potencial de proporcionar uma experiência mais significativa aos alunos. Assim, na Aula 8, realizamos uma explicação teórica sobre condicionais e, durante o restante da aula, os alunos fizeram o desenvolvimento do Pong, utilizando as condicionais para programar algumas das regras do jogo. Embora o site do Scratch ofereça o seu próprio material de apoio, o nome de alguns blocos de comando estão desatualizados no material, o que confundiu os alunos do primeiro semestre. Dessa forma, preferimos criar o nosso próprio material ${ }^{12}$ para que os alunos conseguissem segui-lo mais facilmente.

\section{Aulas 9 e 10: Variáveis no Scratch - Pong}

Nas Aulas 9 e $10^{13}$ foi feita a adição de pontuação ao jogo e a sua customização com o objetivo de torná-lo mais interessante para quem estiver jogando. Para que a pontuação seja adicionada, é necessário a utilização de variáveis, que são simples de serem criadas e manipuladas por meio dos blocos do Scratch. Assim, antes dos alunos iniciarem o desenvolvimento, apresentamos o conceito de variáveis e como elas são especificamente utilizadas no Scratch. Para os alunos que conseguiram finalizar a adição da pontuação, propusemos algumas mudanças a serem realizadas no projeto, sendo elas tanto visuais quanto funcionais: alterar o cenário caso a pontuação chegue a um determinado valor, adicionar uma nova raquete no topo que não pode tocar na bola e adicionar uma nova bola que faz com que a pontuação diminua.

\section{Aula 11: Preparação de Slides}

Nesta última aula os alunos prepararam uma apresentação de slides abordando as atividades do GTD para um encontro de pais. Após a preparação dos slides, deixamos o restante da aula livre para os alunos.

\section{Resultados}

Nesta seção apresentamos e discutimos os resultados do GTD de PC I 2019/2 referentes à preferência dos alunos em relação aos recursos didáticos adotados, à dificuldade dos recursos e às nossas observações. Ambos o Code.org e Scratch foram aplicados em múltiplas aulas, assim os resultados dos questionários são uma agregação das respostas. O Code.org foi aplicado em duas aulas, totalizando 22 respostas coletadas, já o Scratch foi aplicado em quatro aulas, totalizando 42 respostas coletadas. As aulas 6 e 8 tiveram 10 respostas porque um dos alunos faltou nessas aulas.

\section{Preferência dos alunos em relação aos recursos didáticos}

A grande maioria dos alunos avaliou todos os recursos didáticos positivamente nos questionários (Figura 1). Considerando apenas as avaliações positivas, a porcentagem de respostas que foram para o item "adorei" foi maior que as do item "gostei" para todos os recursos avaliados.

\footnotetext{
${ }^{12}$ Aula 8 - Pong: Condicionais $\square$

${ }^{13}$ Aulas 9 e 10 - Pong: Variáveis $\sqsubset$
} 


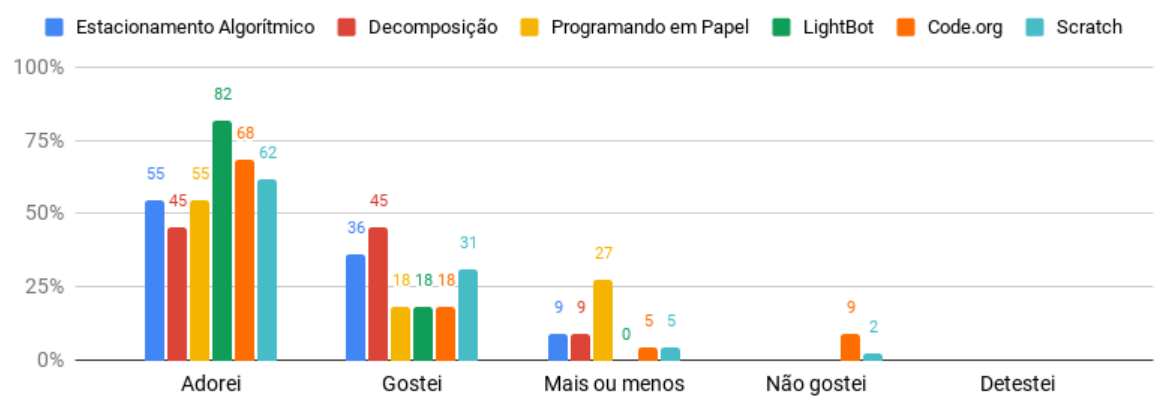

Figura 1. Preferência dos alunos

Similarmente, os comentários dos alunos sobre os recursos didáticos foram bastante positivos nos grupos focais. A maioria mencionou que gostou de tudo que eles fizeram no GTD. O participante G2P4, em especial, afirmou que o GTD de PC I 2019/2 foi a aula mais legal do segundo semestre.

\section{Pesquisador: Vocês não acharam nada chato? \\ G2P4/G2P6/G2P7: Não. \\ G2P4: Sua aula é a mais legal que tem. Da semana...}

Eles apontaram diversos motivos que os fizeram gostar das atividades do GTD tais como (i) as atividades serem desafiadoras, fazendo com que eles raciocinassem bastante, (ii) as atividades serem divertidas, (iii) a possibilidade deles criarem seus próprios projetos no Scratch e (iv) a possibilidade deles poderem aprender e competir durante a realização dos kahoots.

O Code.org e o Scratch foram as únicas ferramentas com respostas negativas nos questionários e grupos focais. Nos grupos focais, apenas dois alunos indicaram não ter gostado destas ferramentas, pois eles acharam ruim ter que ficar arrastando os blocos.

\section{Dificuldade dos Recursos Didáticos}

A Figura 2 apresenta os resultados do questionário referentes à dificuldade das atividades para os alunos. Nenhuma atividade foi avaliada como "muito difícil". Com exceção do Estacionamento Algorítmico, a maioria das respostas foram positivas (i.e.: muito fácil, fácil) para todas as atividades avaliadas, sendo que três delas (i.e.: Decomposição, LightBot e Scratch) foram consideradas como muito fácil por pelo menos $50 \%$ dos alunos.

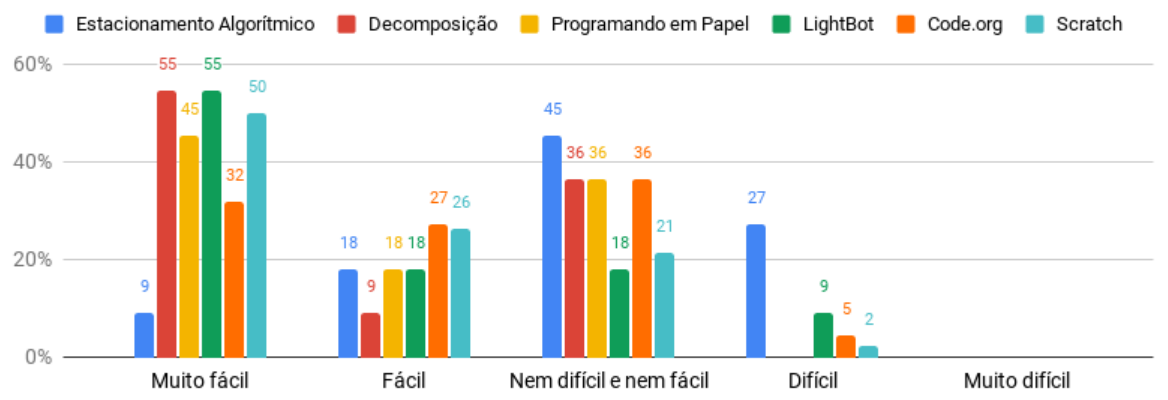

Figura 2. Dificuldade das ferramentas 
O Estacionamento Algorítmico foi considerado fácil por apenas $27 \%$ dos participantes (9\% muito fácil, $18 \%$ fácil) e difícil por $27 \%$ dos alunos. O restante das respostas foram neutras. Contudo, nenhum aluno apontou nos grupos focais que ela foi difícil e, conforme visto previamente, eles consideram que as atividades serem desafiadoras foi um aspecto positivo.

Uma quantidade pequena de alunos considerou o LightBot, Code.org e Scratch difíceis $(9 \%, 5 \%$ e $2 \%$ respectivamente). Em um dos grupos focais os alunos mencionaram que a dificuldade do LightBot fez com que eles gostassem menos dele se comparado às outras atividades.

O Code.org foi a ferramenta com respostas mais equilibradas se considerarmos as duas opções positivas e a opção neutra (32\% muito fácil, $27 \%$ fácil, 36\% nem difícil e nem fácil). Alunos mencionaram nos grupos focais que alguns dos desafios do Code.org foram difíceis, porém eles ainda consideraram que as aulas foram legais.

G2P11: Ah tá. Esse é mais ou menos, mas é legal também.

Pesquisador: Porque é mais ou menos?

G2P11: Ah porque eu achei um pouco difícil. Alguns (desafios), mas era legal.

$$
* * *
$$

G2P9: Eu achei ela legal, só que... Nada. Nada.

Pesquisador: Não, pode falar.

G2P9: É que eu errei.

Pesquisador: Mas você achou ruim isso ou... você achou legal mesmo você tendo errado?

G2P9: Legal.

Os alunos apontaram que os roteiros das atividades do Scratch foram importantes para que eles pudessem realizar as atividades no Scratch. Contudo, alguns deles tiveram dificuldades para encontrar blocos nos roteiros impressos em preto, os quais foram utilizados em todas as aulas com exceção da Aula 7: Scratch - Anime seu Nome. Por exemplo, G2P10 afirmou que a segunda aula no Scratch ficou um pouco entediante pela dificuldade que ela teve ao encontrar os blocos que ela queria utilizar.

\section{Pontos de interesse observados}

Em comparação ao primeiro semestre, percebemos que foi mais fácil para os alunos do segundo semestre lembrarem os passos ao fazer o registro das soluções do Estacionamento Algorítmico assim que um desafio fosse solucionado. Contudo, ainda foi difícil para eles lembrarem exatamente quais foram os veículos movidos e como e em qual ordem eles foram movimentados para que os desafios fossem resolvidos.

A atividade Decomposição da Turma da Mônica e o vídeo exibido na segunda aula, demonstraram ter sido úteis e interessantes aos alunos. Eles entenderam a importância de ordenar corretamente e detalhar bem os passos ao decomporem os problemas da atividade e participaram ativamente quando estávamos discutindo as soluções com a turma. Similarmente, todos estavam atentos ao assistir o vídeo e vários deles deram risadas ao ver as consequências geradas pela má definição dos passos para fazer o sanduíche.

Em relação ao Programando em Papel, os alunos conseguiram acabar os desafios propostos muito rapidamente. Como indicado na descrição da aula, o número de 
exercícios do Programando em Papel foi reduzido uma vez que desafios tinham sido incluídos em excesso no GTD de PC I anterior. Esperávamos que a inclusão da atividade de decomposição e o vídeo na segunda aula compensariam a redução, porém este acabou não sendo o caso.

$\mathrm{Na}$ lição Labirinto: Laços do Code.org, os alunos tiveram grande dificuldade em identificar padrões e transformá-los em repetições para que menos blocos fossem utilizados nos desafios, sendo necessário que nós os ajudássemos individualmente. Assim, na aula seguinte, pedimos que eles, primeiramente, criassem algoritmos sem o bloco de repetição e, em seguida, o analisassem para identificar grupos de comandos que estavam sendo repetidos. Foi observado que essa dica ajudou a turma a resolver alguns dos desafios utilizando a menor quantidade de blocos.

No que diz respeito ao Kahoot!, a reação dos alunos do GTD de PC I 2019/2 ao participarem dos kahoots nos mostrou que a utilização do Kahoot! para revisão de conteúdos pode tornar a experiência mais significativa e engajadora para os alunos. Reações similares foram observadas no GTD de PC I 2019/1. Os alunos também demonstraram ter gostado dos kahoots e de jogá-los, ficando eufóricos e agitados sempre que as respostas eram reveladas. Alguns deles chegaram a pedir para que os kahoots fossem repetidos nas aulas mesmo que as perguntas e respostas fossem sempre as mesmas.

Em algumas aulas do GTD, observamos uma grande discrepância no tempo gasto pelos alunos para finalizar as atividades propostas. Por exemplo, nas aulas onde aplicamos o Code.org, alguns alunos conseguiram terminar os desafios propostos muito rapidamente em relação ao restante da turma. Assim, para evitar que eles ficassem sem nada para fazer, nós disponibilizamos a eles outras lições do Code.org que abordavam o mesmo tema.

Notamos que a maioria dos alunos do GTD de PC I 2019/2 não tinha o costume de utilizar computadores. No princípio, observamos que eles estavam digitando URLs de sites na caixa de texto do Google, que era a página inicial dos navegadores instalados nos computadores. Então, foi necessário que os ensinássemos a como acessar sites digitando URLs. Observamos também que os alunos não tinham consciência de sair de suas contas antes deles fecharem os navegadores e desligarem os computadores. Ademais, vários deles salvaram as credenciais das suas contas nos navegadores, o que não é recomendável uma vez que os computadores da escola são utilizados por várias turmas. No final do GTD, alguns comentários em relação a isso emergiram nos grupos focais.

\footnotetext{
G2P3: Eu não mexia... Eu não mexo muito no computador não. Então, eu não sei nada.

$* * *$

G2P8: Sim. Na minha casa eu nunca mexo no computador.

G2P10: Eu acho legal porque em casa a gente não tem tanto contato com o computador porque a gente fica muito mais no celular do que no computador. Aí agora... a gente sabe mais sobre internet e o que tem disponível no celular. E eu acho legal aprender sobre o computador às vezes. Até pra ensinar os nossos pais.
}

\section{Considerações Finais}

Neste trabalho nós apresentamos o GTD de PC I 2019/2 e os resultados alcançados com a sua condução. Nós avaliamos a experiência a partir de questionários e grupos focais onde os alunos expressaram suas opiniões sobre as diversas atividades realizadas e também a partir de nossas observações ao conduzirmos o GTD. 
Os resultados referentes à preferência dos alunos em relação aos recursos didáticos adotados no GTD foram positivos nos questionários e grupos focais. Com exceção dos dois alunos que mencionaram não ter gostado do Scratch e o Code.org, eles indicaram que gostaram de todas as atividades e todos os 11 alunos mencionaram ter gostado de participar do curso. Desta forma, acreditamos que as atividades do GTD de PC I 2019/2 são interessantes e engajadoras para alunos do EF - Anos Finais.

No que diz respeito à dificuldade, nenhuma atividade foi apontada como muito difícil pelos alunos. Eles conseguiram realizar as atividades propostas por nós no GTD e, embora algumas atividades tenham sido difíceis para alguns deles, não vemos isto como algo negativo dado que esperávamos que eles tivessem certas dificuldades e tentassem superá-las. Ademais, eles expressaram nos grupos focais que gostaram de ser desafiados ao realizar as atividades. Portanto, consideramos que as ferramentas e atividades adotadas no GTD de PC I 2019/2 tiveram dificuldade adequada para os alunos participantes.

Também relacionado à dificuldade das atividades, destaca-se a importância em preparar tarefas extras ou desafios para alunos que tenham desempenho elevado e consigam terminar as tarefas propostas para a aula em pouco tempo. Desta maneira, estes alunos não ficariam ociosos durante o restante da aula, fazendo outras coisas no computador ou distraindo seus colegas de classe. Outra opção a ser considerada é pedir aos alunos que terminarem as tarefas antes do fim da aula para ajudar os seus colegas que estão tendo dificuldades. Esta é uma abordagem interessante que pode ser contribuir para o desenvolvimento das habilidades do PC dos alunos que estão assumindo o papel de ajudantes; no entanto, isto poderia ser prejudicial àqueles sendo ajudados pois os ajudantes poderiam simplesmente fazer as tarefas no lugar dos alunos tendo dificuldades.

O foco do GTD foi o desenvolvimento das habilidades do PC através do aprendizado de tópicos básicos da Computação e a sua prática através da programação. Entretanto, observamos que além do PC, as atividades plugadas do GTD que os alunos tiveram que fazer, também deram oportunidades para os alunos que tinham pouca experiência com computadores de mesa aprendessem mais sobre eles e a como utilizá-los.

Os principais problemas com o curso observados por nós ocorreram nas duas primeiras aulas. No caso do Estacionamento Algorítmico, poderíamos ter pedido aos alunos para que eles fossem anotando os passos em uma folha de rascunho enquanto eles tentavam resolver os desafios para evitar que eles tivessem que relembrar tudo. Em relação ao Programando em Papel, buscamos evitar que a atividade ficasse cansativa ao reduzir o número de desafios, porém a aula acabou ficando curta. Desafios extras poderiam ter sido preparados para serem disponibilizados aos alunos caso fosse necessário.

Os resultados obtidos com a condução dos GTDs em 2019 foram levados em consideração para definirmos uma sequência didática para os professores interessados em fomentar o desenvolvimento do PC nos anos finais do EF. A sequência didática está disponível em [Assunção 2021]. Por fim, os próximos passos do nosso trabalho incluem a avaliação da aplicação desta sequência didática: (i) para ensinar outros grupos de alunos do EF - Anos Finais e (ii) por outros professores interessados em utilizá-la.

\section{Agradecimentos}

Os autores agradecem aos alunos participantes dos GTDs e Oto Braz Assunção agradece ao $\mathrm{CNPq}$ pelo financiamento parcial deste trabalho. 


\section{Referências}

Almeida, W. D. and Junior, A. C. (2020). A aplicação de uma sequência didática no processo de desenvolvimento do pensamento computacional com alunos do $4^{\circ}$ ano do ensino fundamental i. In Anais do XXVI Workshop de Informática na Escola, pages 11-20, Porto Alegre, RS, Brasil. SBC.

Assunção, O., Braga, N., Prates, R., and França, E. (2019). Proposta do uso de múltiplos recursos para o ensino de pensamento computacional no ensino fundamental ii: Um relato de experiência. Anais do Workshop de Informática na Escola, 25(1):1309-1313.

Assunção, O. B. (2021). Proposta de sequência didática para introdução da computação e do pensamento computacional no ensino fundamental ii baseado nas metáforas de perspectivas culturais. Master's thesis, Universidade Federal de Minas Gerais.

Carlos, L., Godinho, J., and Gomide, J. (2018). Um relato de experiência da escola de verão de programação para crianças. In Anais do XXIV WIE, page 41.

Duarte, K., Silveira, T., and Borges, M. (2017). Abordagem para o ensino da lógica de programação em escolas do ensino fundamental ii através da ferramenta scratch 2.0. Anais do Workshop de Informática na Escola, 23(1):175-184.

Heintz, F., Mannila, L., and Farnqvist, T. (2016). A review of models for introducing computational thinking, computer science and computing in k-12 education. In 2016 IEEE Frontiers in Education Conference (FIE).

MEC (2018). Base nacional comum curricular. http://basenacionalcomum.mec.gov.br/. Ministério da Educação. Acessado em: 17-07-2019.

Oliveira, G., Assunção, O., and Prates, R. (2019). Strategies to introduce computational thinking to children: An analysis based on cultural viewpoint metaphors. Brazilian Symposium on Computers in Education, 30(1):547.

Salgado, L. C. D. C., De Souza, C. S., and Leitão, C. F. (2011). On the epistemic nature of cultural viewpoint metaphors. In Proceedings of the 10th Brazilian Symposium on Human Factors in Computing Systems and the 5th Latin American Conference on Human-Computer Interaction, pages 23-32. Brazilian Computer Society.

Santos, P. C., Araujo, L. G., and Bittencourt, R. A. (2018). A mapping study of computational thinking and programming in brazilian k-12 education. In 2018 IEEE Frontiers in Education Conference (FIE), pages 1-8.

SBC (2019). Diretrizes para ensino de computação na educação básica. http://www.sbc.org.br/documentos-da-sbc/send/203-educacao-basica/1220-bnccem-itinerario-informativo-computacao-2. Acessado em: 12-04-2021.

Spradley, J. P. (1980). Participant Observation. Holt, Rinehart and Winston, 1 edition.

Tripp, D. (2005). Pesquisa-ação: uma introdução metodológica. Educação e pesquisa, pages 443-466.

Wing, J. M. (2006). Computational thinking. Communications of the ACM, pages 33-35.

Wing, J. M. (2011). Computational thinking - what and why? https://www.cs.cmu.edu/link/research-notebook-computational-thinking-what-andwhy. Acessado em: 12-04-2021. 